NBER WORKING PAPER SERIES

\title{
TARGETED EXPORT PROMOTION WITH SEVERAL \\ OLIGOPOLISTIC INDUSTRIES
}

Avinash $K$. Dixit

Gene M. Grossman

Working Paper No. 1344

NATIONAL BUREAU OF ECONOMIC RESEARCH

1050 Massachusetts Avenue

Cambridge, MA 02138

May 1984

We are grateful for financial support provided by the National Science Foundation under grants SES-8308536 and PRA-8211940 and the International Labor Affairs Bureau, U.S. Department of Labor under contract J9K30006. We also thank Assaf Razin and Carl Shapiro for helpful comments. The research reported here is part of the NBER's research program in International Studies. Any opinions expressed are those of the authors and not those of the National Bureau of Economic Research. 
NBER Working Paper \#1344

May 1984

Targeted Export Promotion With

Several Oligopolistic Industries

$\underline{\text { ABSTRACT }}$

In this paper we ask whether a policy of targeted export promotion can raise domestic welfare when several oligopolistic industries all draw on the same scarce factor of production. Our point of departure is one of Cournot duopoly in which a single home firm competes with a single foreign firm in a market outside the home country. It has been shown previously that when there is only one such industry in an otherwise perfectly competitive world economy, a subsidy policy by the home government transfers profits to the domestic firm, and thereby raises domestic welfare. However, when many such industries (and only these) utilize the same inelastically supplied resource, promotion of one bids up the return to the specific factor, and consequently disadvantages all of the non-targeted industries in their respective duopolistic competitions. Our question then is which industry(s), if any, is worthy of promotion.

We find that, when the specific factor is used in fixed proportion to output, and all of the duopolies have similar demand and cost conditions, a policy of free trade is optimal. We identify the conditions for welfare improvement when a single industry is selected for targeting under asymmetric conditions, and also investigate whether a uniform subsidy to all industries in the imperfectly competitive sector will raise domestic welfare.

Avinash K. Dixit

Woodrow Wilson School

Princeton University

Princeton, NJ 08544

(609) 452-5635
Gene M. Grossman

Woodrow Wilson School

Princeton University

Princeton, NJ 08544

(609) 452-4823 


\section{INTRODUCTION}

Subsidies that assist domestic firms in their competition with foreign rivals are being viewed with increasing favor, both in theoretical analyses and in practical applications. Conventional economic reasoning regarded them as inappropriate instruments of trade policy. Any terms-of-trade advantage would be pursued by restricting trade through tariffs, not by promoting it using subsidies. A production subsidy to an import-competing industry would be an inferior substitute for a monopoly-optimum tariff, while such a subsidy to an exporting industry would actually worsen the terms of trade.

The recent shift in the theoretical stance comes from a recognition of the importance of oligopolistic competition in many industries. When monopoly rents exist, a policy that transfers these rents from foreign firms to domestic ones offers an element of national advantage. This is seen most clearly in a case where the home market is not involved, so the relevant contribution to home welfare is simply the home firms' profits. Now consider a Cournot duopoly with a home firm and a foreign firm. A subsidy to the home firm moves the equilibrium along the foreign firm's reaction function towards the home firm's leadership point, i.e. favorably to the home country. Spencer and Brander (1983) gave the first clear example of such rent-extracting policies in the context of R\&D.

Subsequent research has extended and modified this conclusion. Dixit (1984) considers a somewhat more general Cournot oligopoly where the home market is also involved, and possible trade-offs with consumer surplus must be considered. He shows that the presumption for optimal policy turns against subsidization as the number of domestic firms increases. More fundamentally, Eaton and Grossman (1983) consider 
alternative forms of oligopolistic competition and show that policy conclusions are very sensitive to the specification of the industry equilibrium. In a Bertrand duopoly, for example, the rent-shifting motive for policy intervention presumptively indicates a production or export tax. With consistent conjectural variations, the transfer of rents to the home firm is impossible, and free trade is optimal.

In this paper we shall focus on yet another difficulty with the rent-extraction argument, which is of considerable practical importance in the current context of U.S. trade policy. The models constructed so far have considered one oligopolistic industry in an otherwise perfectly competitive economy. When this industry is subsidized, it expands by drawing resources from other uses where prices equal marginal costs, and there are no rents to be lost. However, if several industries are oligopolistic, we must consider the possibility that promoting rent-extraction in one industry will at the same time cause an even greater rent loss in another. The problem is especially serious if a whole sector of such industries uses a specific factor, and all the industries in the sector must compete with each other in bidding for the services of this factor.

Consider the frequent arguments for promotion of the "high technology" sector in the U.S. in the light of this. The sector actually comprises many different industries. Most are at a stage of development where world competition will remain oligopolistic for some time to come. Almost all require significant quantities of scientifically skilled labor, whose supply involves long lags in training and is therefore quite inelastic over the time span where the market is oligopolistic. It is 
doubtful indeed that all these industries could expand simultaneously at any given point in time.

In such a situation, the design of correct policies involves much more subtle analysis. We must disaggregate to the industry level, and devise principles that allow us to identify those that merit targeted help. In doing so, we recognize the general equilibrium principle that promotion of one industry is implicitly taxation of another. When discrimination by industry is not possible, we have to ask whether a uniform subsidy to the whole sector is worthwhile. Finally, we have to consider the alternative forms of assistance, and determine which is best.

In this paper we construct a simple model that allows us to answer many of these questions. After describing the model and the first-best allocation in Section 2, we consider in Section 3 the efficacy of production or export subsidies targeted to specific industries. In Section 4 we study a policy of uniform subsidization of the entire imperfectly-competive sector. Finally, in Section 5 we note some caveats and extensions of the analysis.

\section{THE MODEL}

As usual, we construct the simplest model that allows us to focus on the issue of central concern, namely policy towards oligopolistic traders who compete for a specific factor. We assume there are two factors of production; for sake of concreteness we call them workers and scientists. All outputs other than those of the oligopolistic high-technology industries are aggregated into one good, which is assumed to be produced by workers alone under constant returns to scale and perfect competition. 
We choose this good as numeraire, and measure it in units which make the input-output coefficient equal to one. Then the workers' wage w will equal 1 in equilibrium.

The high-technology sector consists of a number of industries, labelled $i=1,2, \ldots n$. One unit of good $i$ is produced using one unit of scientists' labor (choice of scales again) and $a_{i}$ worker-hours. If $z$ denotes the scientists' wage, the marginal cost of production is $\left(a_{i}+z\right)$. Factor markets are assumed to be competitive, therefore this is regarded as constant by each individual firm. There may be fixed costs which explain the oligopolistic market structure, but we do not need to account for them explicitly. We will comment on the consequences of relaxing the fixed-coefficient assumption in Section 5 .

Consider the country active in export promotion policy, called the home country. Let $x$ be its output of the numeraire good, $y_{i}$ that of the $i^{\text {th }}$ high-technology industry, $L$ the fixed supply of workers, and $S$ that of scientists. Then the factor market equilibrium conditions are

$$
\begin{array}{r}
x+\Sigma_{i} a_{i} y_{i}=L \\
\Sigma_{i} y_{i}=S
\end{array}
$$

Each high-technology industry is an oligopoly involving domestic and foreign firms. In conformity with the simplest model of rent-extraction, we assume this to be a Cournot duopoly (i.e. one domestic firm and one foreign firm per industry). Also, to avoid complications caused by the consumer surplus in the home market, we assume that the home consumption 
of the high-technology products is negligible. Discussion of the consequences of relaxing these assumptions is postponed until section 5 .

Consider the $i^{\text {th }}$ industry. Let $Y_{i}$ be the output of the foreign firm, and $r^{i}\left(y_{i}, Y_{i}\right)$ the revenue function of the home firm. With no home consumption, there is no difference between export subsidies and production subsidies. Let $s_{i}$ be the subsidy per unit output of $i$. Then the home firm's first-order condition for profit-maximization is

$$
r_{i}^{i}\left(y_{i}, Y_{i}\right)=a_{i}+z-s_{i}
$$

where the subscript 1 denotes partial differentiation with repect to the first argument. The corresponding condition for the foreign firm can be summarized in a "reaction" function"

$$
Y_{i}=B_{i}\left(y_{i}\right)
$$

Any policy variables of the foreign government are hidden as parameters in the $B_{i}$, since we are not considering a strategic game of policy. If we did, at its Nash equilibrium, the home country's optimum choices would continue to be determined as in our analysis, where the $B_{i}$ would then be interpreted to correspond to the equilibrium policy choices of the foreign government.

Equations (2)-(4) can be solved for $y_{i}, Y_{i}$ for $i=1,2, \ldots n$ and for $z$, and then $x$ can be found from (1). A special case permits explicit solution, and we will occasionally use it to illustrate some points of detail. In it, the inverse demand functions are linear: for the home firm (omitting the label $i$ for ease of notation) 


$$
p=\pi-\tau y-k Y
$$

and for the foreign firm,

$$
P=\Pi-\kappa y-T Y
$$

We assume the products to be substitutes, i.e. $K>0$. Demand theory gives $\tau, T$ positive, and $\left(\tau T-\kappa^{2}\right) \geq 0$, with equality if the home and foreign varieties are perfect substitutes. Then

$$
r(y, Y)=\pi y-\tau y^{2}-k y Y
$$

and

$$
Y=B(y) \equiv(\Pi-C-k y) /(2 T)
$$

where $C$ is the exogeneous and constant marginal cost of the foreign firm. Returning to the general case, the criterion of social welfare in the home country is simply the sum of factor incomes and profits, minus the cost of subsidies:

$$
W=L+z S+\Sigma_{i}\left\{r^{i}-\left(a_{i}+z-s_{i}\right) y_{i}\right\}-\Sigma_{i} s_{i} y_{i}
$$

Using (1) - (4), this can be expressed in terms of output quantities:

$$
w=x+\Sigma_{i} r^{i}\left(y_{i}, B_{i}\left(y_{i}\right)\right)
$$


We are now ready to consider various issues involving choice of subsidy policies. The general idea is that changes in the subsidy rates $s_{i}$ will shift the home firms' "reaction" functions defined by (3), and will move the oligopoly equilibria along the foreign firms' "reaction" functions (4). For each $i$, there will be a most favorable choice of $y_{i}$, namely the Stackelberg leadership point. But the scarcity of the specific factor as reflected in (2) can prevent the simultaneous attainment of these points for all.i. The scientists' wage $z$ will rise, thereby producing a second and adverse effect on the home reaction functions .

The necessary trade-offs will be judged at the most general level by choosing $x$ and the $y_{i}$ to maximize (5) subject to (1) and (2), or substituting for $x$, maximize

$$
W=L+\Sigma_{i}\left\{r^{i}\left(y_{i}, B_{i}\left(y_{i}\right)\right)-a_{i} y_{i}\right\}
$$

subject to (2). Then we can find the $s_{i}$ that will sustain this optimum from (3). This is the first-best, constrained only by resource availability, technology, and the Cournot reactive behavior of the foreign firm.

Let $z$ denote the Lagrange multiplier on the constraint (2), in view of its economic significance. Then the first-order conditions are, for $i=1,2, \ldots n$

$$
r_{1}^{i}+r_{2}^{i} B_{i}^{\prime}-a_{i}-z=0
$$




$$
\phi_{i}\left(y_{i}\right)=r_{2}^{i}\left(y_{i}, B_{i}\left(y_{i}\right)\right) B_{i}^{\prime}\left(y_{i}\right)
$$

With $r_{2}^{i}<0$ and $B_{i}^{\prime}<0$ as in usual Cournot duopoly, we have $\phi_{i}>0$. Then, comparing (7) and (3), we see that the first-best can be sustained by means of subsidies $s_{i}=\phi_{i}$. This is the standard rent extraction argument. A marginal increase in the home firm's output has a twofold effect on its revenues and profits. The first is the marginal revenue $\mathrm{r}_{1}^{i}$ holding the foreign firm's output constant. But there is also a profit-shifting effect, as the foreign firm moves down its "reaction" function and the price of home output goes up. The home firm, given its Cournot behavior, neglects the latter. If the government can calculate it and implement a subsidy of that amount before the duopoly game is played, the firm's calculation will reflect the full effect.

But the scarcity of the specific factor makes an important difference. Although $s_{i}>0$ for all $i$, this does not mean an increase in all $\mathrm{y}_{i}$ above their free trade levels. Inspection of (2)-(4) shows that if all the $s_{i}$ are raised by one unit, the new equilibrium has all the $y_{i}$ unchanged, and $z$ increased by one unit. Thus only differential subsidy rates affect allocations. If a general subsidy is applied, the real beneficiaries are the scientists whose wages rise. We do not think that arguments for broad support for high-technology as a whole are motivated by a desire to increase the rent to scarce scientific skills. But the fact, and its possibly adverse distributional consequences, should be borne in mind by policy-makers in practice.

In the linear example, we can calculate the output effects explicitly. Let the superscript $f$ denote free trade, and 0 the first-best optimum. Then we can show that 


$$
y_{i}^{o}-y_{i}^{f}=\delta_{i}\left[s_{i}-\left(z^{o}-z^{f}\right)\right]
$$

where

$$
\delta_{i} \equiv 2 \mathrm{~T}_{i} /\left(4 \tau_{i} \mathrm{~T}_{i}-k_{i}^{2}\right)>0
$$

in the notation of $\left(3^{\prime}\right)$ and $\left(4^{\prime}\right)$ with industry labels appended. But, using (2) for both equilibria,

$$
\Sigma_{m}\left(y_{m}^{o}-y_{m}^{f}\right)=0
$$

Therefore

$$
z^{0}-z^{f}=\Sigma_{m} \delta_{m} s_{m} / \Delta
$$

where $\Delta \equiv \Sigma_{m} \delta_{m}$. Substituting $s_{i}=\phi_{i}$ in the first-best, we see that

$$
y_{i}^{o}>y_{i}^{f} \text { if and only if } \phi_{i}>\Sigma_{m} \delta_{m} \phi_{m} / \Delta
$$

i.e. the profit-shifting effect of an output increase in industry i exceeds the $\delta$-weighted average of such effects for the whole sector. We will come across similar comparisons in other policy contexts in Section 3 and 4 .

Next consider second-order conditions for the maximization of (6). The constraint (2) being linear, a sufficient condition is that $\mathrm{r}^{i}\left(\mathrm{y}_{i}, \mathrm{~B}_{i}\left(\mathrm{y}_{i}\right)\right)$ should be concave in $\mathrm{y}_{i}$, i.e. ${ }^{2}$ 


$$
\left\{r_{11}^{i}+2 r_{12}^{i} B_{i}^{\prime}+r_{22}^{i}\left(B_{i}^{\prime}\right)^{2}\right\}+r_{2}^{i} B_{i}^{\prime !}<0
$$

For this, in turn, it is sufficient to have $r^{i}\left(y_{i}, Y_{i}\right)$ concave (which ensures that the bracketed expression is negative) and the foreign reaction function convex $\left(\mathrm{B}^{\prime \prime}{ }_{i}>0\right)$. It is easy to verify that the linear case poses no problems. But in general it is not possible to assume that the second-order conditions will hold. If they fail, the first-best optimum will invole the identification of one industry and promoting it at the expense of all others. However, the informational requirements of this are clearly formidable.

\section{TARGETED SUBSIDIES}

The first-best optimum choice of subsidies considered in the previous section is usually remote from practial considerations of policy. One reason is the political constraint on the government's budget which finances the subsidy. Other reasons have to do with information and computation. The welfare effects of small changes in policy from the status quo can be computed using information about demands and costs in the neighbourhood of the initial point. This is more easily available and more reliable than the global information needed to compute the first best. Finally, the political process may admit policy changes only on an incremental basis, for fear of the consequences of radical departures. These reasons motivate the "tax reform" approach in the theory of public finance (e.g. Feldstein (1976)), and we invoke them to justify attention to small changes in the subsidy rates from an initial situation of free trade. 
When the subsidy rates $\left(s_{i}\right)$ change by $\left(d s_{i}\right)$, we differentiate (3) and (4) totally and write

$$
\left(r_{11}^{i}+r_{12}^{i} B_{i}^{i}\right) d y_{1}=1 z-d s_{i}
$$

or

$$
d y_{i}=\delta_{i}\left(d s_{i}-d z\right)
$$

where

$$
\delta_{i} \equiv-1 /\left(r_{11}^{i}+r_{12}^{i} B_{i}^{\prime}\right)
$$

The Cournot stability condition on the relative slopes of the "reaction" functions gives $\delta_{i}>0$. This usage of $\delta_{i}$ is consistent with that defined for the linear example in the previous section; indeed, we see that the local results above hold for large changes in the special case.

Now, differentiating (2), we have

$$
0=\Sigma_{m} d y_{m}=\Sigma_{m} \delta_{m} d s_{m}-d z \Sigma_{m} \delta_{m}
$$

or,

$$
\mathrm{d} z=\Sigma_{\mathrm{m}} \delta_{\mathrm{m}} \mathrm{ds} \mathrm{m} / \Delta
$$

Then

$$
d y_{i}=\delta_{i}\left\{d s_{i}-\Sigma_{m} \delta_{m} d s_{m} / \Delta\right\}
$$

In terms of partial derivatives,

$$
\partial z / \partial s_{i}=\delta_{i} / \Delta>0 \quad \text { for all } i
$$

and 


$$
\frac{\partial y_{i}}{\partial s_{j}}= \begin{cases}\delta_{i}\left(1-\delta_{i} / \Delta\right)>0 & \text { for } i=j \\ -\delta_{i} \delta_{j} / \Delta<0 & \text { for } i \neq j\end{cases}
$$

In the linear example, the $\delta_{i}$ are constants, and then so are all these derivatives.

Next we differentiate the expression (6) for welfare:

$$
d W=\Sigma_{k}\left(r_{1}^{k}+r_{2}^{k} B_{k}^{\prime}-a_{k}\right) d y_{k}
$$

Using (3) (with $s_{i}=0$ at the initial point) and the definition of $\phi_{i}$, this becomes

$$
\begin{aligned}
\mathrm{dW} & =\Sigma_{\mathrm{i}}\left(z+\phi_{\mathrm{k}}\right) \mathrm{dy} \mathrm{k}_{\mathrm{k}} \\
& =\Sigma_{\mathrm{k}} \phi_{\mathrm{k}} \mathrm{dy_{ \textrm {k } }} \text { using (2) } \\
& =\Sigma_{\mathrm{k}} \phi_{\mathrm{k}} \delta_{\mathrm{k}}\left\{\mathrm{d} \mathrm{s}_{\mathrm{k}}-\Sigma_{\mathrm{m}} \delta_{\mathrm{m}} \mathrm{ds} \mathrm{m}_{\mathrm{m}} / \Delta\right\} \text { using (12) } \\
& =\Sigma_{\mathrm{k}} \phi_{\mathrm{k}} \delta_{\mathrm{k}} \mathrm{ds} \mathrm{s}_{\mathrm{k}}-\Sigma_{\mathrm{k}} \phi_{\mathrm{k}} \delta_{\mathrm{k}} \Sigma_{\mathrm{m}} \delta_{\mathrm{m}} \mathrm{ds}_{\mathrm{m}} / \Delta
\end{aligned}
$$

Hence

$$
\partial W / \partial s_{i}=\delta_{i}\left\{\phi_{i}-\Sigma_{k} \phi_{k} \delta_{k} / \Delta\right\}
$$

We conclude from (15) that a small subsidy to the $i^{\text {th }}$ industry will increase welfare if

$$
\phi_{i}>\Sigma_{m} \phi_{m} \delta_{m} / \Delta
$$


i.e. its profit-shifting effect exceeds the $\delta$-weighted average of such effects for the whole group of high-technology industries. If the opposite inequality holds, a small tax on this industry is called for.

The explanation lies in the fact that the outputs of these industries are together constrained by the availability of the scientists' labor. Thus, in (14), the subsidy to industry i raises its output, but lowers the output of each of the other industries. The positive profit-shifting effect of the former change must then be. compared to the negative effects of the latter changes. This is why the industries with the strongest profit-shifting effects are to be encouraged and those with the weakest ones discouraged. The exact criterion is stated in (14). Since the $\delta_{i}$ govern the strength of the output responses, it makes sense to have them serve as the weights.

For notational simplicity, we took all the scientific-labor input coefficients to be equal to one. If we had carried them along as general sumbols $b_{i}$, the comparison in (16) would set $\left(\phi_{i} / b_{i}\right)$ against its weighted average. What really matters is the profit-shifting effect generated in industry $i$ per unit of additional scientific labor used there.

Needless to say, the correct calculation of the choices of industries for targeted subsidies involves some subtle reasoning and quite demanding information. The danger of errors in practical implementation seems substantial.

In a symmetric case where all the $\phi_{i}$ are equal (or when, in the absence of any reliable discriminating information, the planner treats them as equal), we have $d W=0$ at the initial point. Thus free trade satisfies the first-order conditions for optimality. The second-order condition (9) again applies, now holding in common for all $i$. This can 
be verified for the linear example, but raises a potential problem in general. With this proviso, we see that free trade is optimal for a symmetric group of industries. When industries are indistinguishable as candidates for targeting, and when all draw on a common, inelasticallysupplied resource, there is no benefit from selecting any one of them for promotion (unless the profit-shifting effects are increasing in output, in which case a single industry should be chosen for targeting).

\section{UNIFORM SUBSIDY}

In practice, we may be constrained to choosing a common rate of subsidy for all industries in this sector. If they have different profit-shifting effects, it is not clear that such a subsidy will be beneficial. We investigate the issue now.

Such a common subsidy rate is more reasonable in ad valorem form, and not per unit of output. Therefore we take

$$
d s_{i}=\left(a_{i}+z\right) d \sigma
$$

Then, from (15)

$$
\begin{aligned}
\mathrm{d} W / \mathrm{d} \sigma= & \Sigma_{i}\left(a_{i}+z\right) \partial W / \partial s_{i} \\
= & \Sigma_{i} a_{i} \phi_{i} \delta_{i}-\Sigma_{i} a_{i} \delta_{i} \Sigma_{k} \phi_{k} \delta_{k} / \Delta \\
& +\left\{\Sigma_{i} \phi_{i} \delta_{i}-\Sigma_{i} \delta_{i} \Sigma_{k} \phi_{k} \delta_{k} / \Delta\right\} z
\end{aligned}
$$




$$
=\Delta\left\{\frac{\sum_{i} a_{i} \phi_{i} \delta_{i}}{\Delta}-\frac{\sum_{i} a_{i} \delta_{i}}{\Delta} \frac{\sum_{m} \phi_{m} \delta_{m}}{\Delta}\right\}
$$

The bracketed expression is the $\delta$-weighted covariance between the $a_{i}$ and the $\phi_{i}$. In this sense, if on the average the industries with large profit-shifting effects are also relatively worker-intensive, then a small subsidy to the sector as a whole will increase welfare. In the more general form with $b_{i}$ as the input coefficients for scientific labor, what is at stake is the correlation between $\left(a_{i} / b_{i}\right)$ and $\left(\phi_{i} / b_{i}\right)$. The point is that a given ad valorem subsidy translates into a bigger subsidy per unit of scientific labor if $\left(a_{i} / b_{i}\right)$ is bigger; this is a good policy if $\left(\phi_{i} / b_{i}\right)$ is correspondingly larger.

Away from the initial position of iree trade, we can perform a similar, but more tedious, calculation. A common ad-valorem subsidy rate $\sigma$ has $s_{i}=\left(a_{i}+z\right) \sigma$, and a small change yields ds ${ }_{i}=\left(a_{i}+z\right) d \sigma$. We can then compute $d W / d \sigma$, and find the $\sigma$ which sets it to zero. We have

$$
\sigma=\operatorname{Cov}\left(a_{i}, \phi_{i}\right) / \operatorname{Var}\left(a_{i}\right)
$$

in the previously defined $\delta$-weighted sense. Subjẹt to the usual second-order conditions, this yields the optimum uniform policy towards the high-technology sector. The sign of $\sigma$ is that of the correlation between $a_{i}$ and $\phi_{i}$. In the symmetric case, free trade is again optimal. 4

\section{CONCLUDING COMMENTS}

In this paper we have argued that the rent-extraction argument for export promotion must be severely qualified when the industries where rent-extraction is possible compete for the services of a specific factor 
that is essential to production. In such circumstances, only those industries with above-average rents in relation to their requirements of this factor at the margin deserve promotion; those below the average should be discouraged. If the industries are equal in this regard, or if the information necessary to discriminate among them is lacking, free trade is optimal.

In conclusion, we comment on the consequences of changing some of the special assumptions of our model. That of fixed coefficients is the most significant. If input substitution is allowed, the whole group of industries can expand to some extent at the expense of the numeraire good. This strengthens the argument for subsidies. To see this explicitly, make the input coefficients functions $a_{i}(z), b_{i}(z)$ with $a_{i}$ increasing and $b_{i}$ decreasing. Then calculations similar to those in Section 3 yield

$$
\frac{\partial W}{\partial s_{i}}=\delta_{i}\left\{\phi_{i}-\frac{\Sigma_{m} \phi_{m} \delta_{m}}{\Delta-\Sigma_{m} y_{m} b_{m}^{\prime}}\right\}
$$

where the initial point has free trade, and units have been chosen so that all the $b_{i}$ equal one at that point. Since the $b_{i}^{\prime}$ are all negative, the denominator in (19) is larger than that in (15). Therefore subsidies to some industries with below-average $\phi_{i}$ may be beneficial.

Our assumption of fixed marginal costs of production in the foreign industries has allowed us to convey the intuition of our arguments in a relatively simple framework. However, if the foreign country has an interlinked production structure in the high technology sector that is similar to that in the home country, then domestic subsidy policy could induce a change in the return to foreign scientists, which would alter 
foreign marginal costs and thereby cause the foreign reaction schedules to shift. The resulting second-round effects on domestic profits thus far have been neglected in the analysis.

A benchmark case to consider is one in which all the home firms are symmetric (i.e. have the same production and revenue functions), as are all the foreign firms, though the home and foreign firm in a given industry may differ from each other. Then we can show that, about the free trade point, (or any other point at which the domestic firms receive equal rate subsidies) a small change in the subsidy to any sector has no effect on the equilibrium wage earned by foreign scientists. It follows that for this case, our calculations in Section 3, which omit any change in the foreign scientists wage extend immediately to the more general specification. In particular, free trade at home remains optimal, provided that the second-order sufficiency conditions are satisfied. When the industries are not symmetric at home or abroad, incorporation of the induced changes in foreign marginal costs in response to domestic policy changes significantly complicates the calculations. For this reason the information and computation requirements for welfareimproving targeted promotion become all the more severe.

The effects of many other assumptions are not central to the issue. Allowing home consumption will affect the desirability of policies that change the final price. It will also require a greater refinement of policy instruments, e.g. distinction between production and export subsidies, and introduction of import tariffs. Considerations of several firms, and non-Cournot conduct, will affect the rent-extraction possibilities themselves. But all these points are fairly well known from other work, and we do not expect to shed new light on them in 
connection with the issue of competition among a group of oligopolistic industries. 


\section{FOOOTNOTES}

1. By writing (4) in this way, we implicitly are assuming that the high technology sector in the rest of the world does not have the same interlinked production structure as exists at home. This assumption simplifies the exposition considerably without significantly affecting the tenor of the conclusions. Alternatively, we could specify a complete two-country general equilibrium structure in which an inelastically-supplied specific factor constrains the expansion of the foreign high technology sector in a manner similar to that in the home country. Then the foreign reaction function would be written as $Y_{i}=B_{i}\left(y_{i}, Z\left(Y_{1}, Y_{2}, \ldots, Y_{n}\right)\right)$, where $Z$ is the salary of foreign scientists. We postpone discussion of this case until Section 5 .

2. As in consumer theory, we really want $W$ to be quasi-cacave in $\left(y_{1}, y_{2}, \ldots, y_{n}\right)$. Concavity of each $r^{i}$ is clearly sufficient. Since $W$ is additiviely separable, it is also "almost" necessary, see Gorman (1976).

3. Incidentally, (11) shows that equal changes in subsidy rates to all industries simply changes $z$ by an equal amount with no effect on the allocation. Thus the first-best in Section 2 could be sustained by alternative policies with lower subsidy rates all around.

4. Note however, that subsidizing all of a group of symmetric industries uniformly is equivalent to subsidizing none of them, so that home welfare is flat over the range of uniform subsidy rates in this case. 


\section{References}

Dixit, A.K. (1984) "International trade policies for oligopolistic industries," Economic Journal, vol. 94, Supplement, forthcoming.

Eaton, J. and Grossman, G.M. (1983) "Optimal trade and industrial policy under oligopoly," Working Paper No. 1236, National Bureau of Economic Research.

Feldstein, M.S. (1976) "On the theory of tax reform," Journal of Public Economics, 6, pp. 77-104.

Gorman, W.M. (1976) "Tricks with utility functions," in M.J. Artis and A.R. Nobay (eds.) Essays in Economic Analysis, Cambridge University Press.

Spencer, B. and Brander, J.A. (1983) "International R\&D rivalry and industrial strategy," Review of Economic Studies, 50, pp. 707-722. 